\title{
From a Quality Assurance and Control System for Medical Processes, Through Epidemiological Trends of Medical Conditions, to a Nationwide Health Project
}

\author{
Yossy Machluf 1,2, Amir Navon ${ }^{1}$, Avi Yona ${ }^{1}$, Avinoam Pirogovsky1,3, \\ Elio Palma ${ }^{1,4}$, Orna Tal ${ }^{5}$, Nachman Ash ${ }^{6}$, Avi Cohen ${ }^{1}$ and Yoram Chaiter ${ }^{1}$ \\ ${ }^{1}$ Quality Assurance and Control Committee, Medical Corps, IDF, \\ ${ }^{2}$ Weizmann Institute of Science, Rehovot, \\ ${ }^{3}$ Head of Standards and Regulation Department in the Division \\ of Community Medicine, Ministry of Health, Tel Aviv, \\ ${ }^{4}$ Head of Department of Occupational Medicine, Clalit Health Services, Afula, \\ ${ }^{5}$ Israeli Center for Technology Assessment in Health Care; The Gertner Institute for \\ Epidemiology and Health Policy Research, Head of Emerging Technologies Unit, Tel Aviv, \\ ${ }^{6}$ Chief Medical Officer, Medical Corps, IDF, \\ Israel
}

\section{Introduction}

A health policy is an integral part of the general welfare policy in every state. According to Dye (1987), interior public policy constitutes the same action as a government that chooses to "do or not do" (Dye, 1987), and thus it is assumed that any governmental action is derived from its will to preserve and provide quality services to the public. Quality of patient health care is defined by two principal dimensions: access and effectiveness (Campbell et al., 2000). Over the last few decades, quality control has been gaining a central place in public organizations in order to improve the quality of services and treatment (Blumenthal, 1996; Landon, et al., 2003; Mandel, et al., 2003; 2004). Quality assurance is a key component in the processes aimed at improving the quality of service and medical care.

\subsection{Quality control and the health system}

The quality index in the health system is a criterion that shows measurable values in morbidity and service levels (Campbell et al., 2000). Since the 1960s, the quality indices in health systems were divided into three main levels: infrastructure and structure, process, and outcome. The last two are usually included as preferred measures (Donabedian, 2005). Infrastructure and structure indices are related to organizational issues of the health services, the attending person's nature, and the procedures and medical policy that are being implemented by the organization on both the private and public levels. The assumption is that any health organization should be capable of providing quality health services according to its resources, which are made up of human, economical, and 
infrastructure components. Process indices are aimed at examining the extent of the medical actions that are taken to achieve the desired target, assuming that well performed operations increase the chance of accomplishing the desired effects. By contrast, outcome indices focus on the individual level rather than on the organization level. Outcome measurements provide an indirect measure of the overall quality assessment and may provide a benchmark for tracking progress. In general, the more the first two indices (the infrastructure and structure and the process indices) are involved in measuring quality, the greater the reliability of the outcome measures (Donabedian, 2005).

Many approaches were developed to assess the quality of health care and to improve both medical and patient processes, such as the Six Sigma, which utilizes the DMAIC model (Define, Measure, Analyze, Improve, and Control); ISO (International Organization for Standardization); BOS (Business Operating System); CI (Continuous Improvement); TQM (Total Quality Management); etc. (Donabedian, 2003; Munro, 2009; Ovretveit, 1992; Ransom et al., 2008). Many of these approaches are derived and adapted from quality assurance systems in industry, where processes are straightforward and the implementation of such methods is easier. Yet, the medical process represents an intricately interwoven and dynamic process (Donabedian, 2003, Ovretveit, 1992) where many variables are interconnected. For instance, in medical committees, managing authorities, health care medical professionals, technical and administrative personnel, and patients, as well as medical policy, regulations, and goals are all part of medical processes. Therefore, difficulties may arise while applying these methods to medical procedures.

Although there are many models of health care quality control and assurance, most focus on specific issues and are a tool for managerial decisions and not for the day-to-day surveillance of the processes on a clinical level. They may address a specific issue at a local medical facility and may try to improve the specific circumstances, such as the high rates of certain infections at a specific ward or at a specific medical center. Most of the quality assurance processes measure outcomes rather than the completeness and intactness of the continuous process and use a set of tracers or specific indicators, such as Hemoglobin A1C levels in diabetics, cholesterol levels, blood pressure, etc. There are also many economical issues addressed by such quality assurance systems and only rarely do they achieve an optimal resolution of the processes that they aim to control. Many decisions are made in an effort to save expenses and by that to achieve control, while the clinical issues of the processes are not addressed in detail. Most quality systems deal with a limited aspect of the health care process, rather than dealing with the whole process and its various components, including both personnel (policy makers, managers, medical professionals, technical staff, administrative shell, patients) and non-personnel (policy, regulations, infrastructure, economy). In this chapter, the design, application, and outcomes of a unique quality control and assurance program within the framework of medical committees will be described.

\subsection{Overview of medical processes at recruitment centers}

In Israel, adolescents aged 16-19 are obligated by law to enlist for military service and are examined by medical committees at conscription centers in order to determine their medical status. The medical process at the recruitment centers necessitates the coordinated action of medical professionals, technical and administrative personnel, and managing authorities, on both the local and national levels. The medical process is based mainly on a medical interview and an examination by a medical committee and is supplemented and supported by information from the family physician, medical consultants, and experts (Fig. 1). 


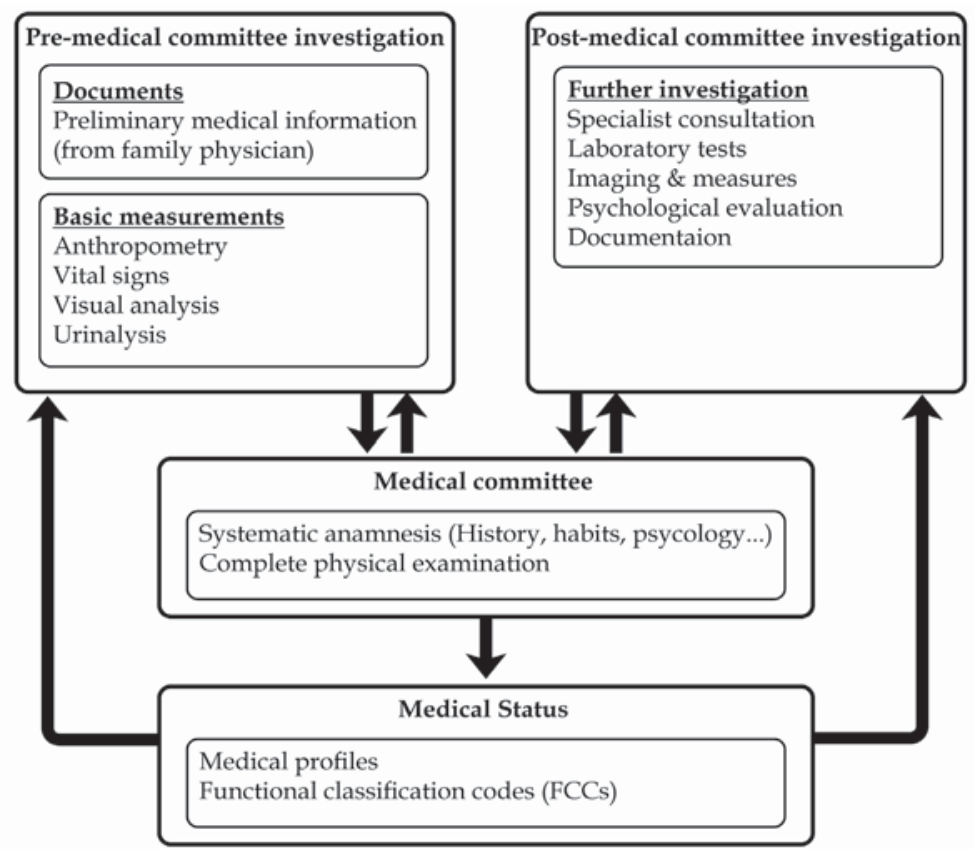

Fig. 1. Schematic representation of the medical process at the recruitment centers.

The administrative medical department employees at the recruitment centers constitute the administrative shell of the medical process, are thought of as medical facility workers, and serve as an extension of the medical process. They are exposed to medical information and follow strict laws of keeping medical confidentiality. They are in charge of the appointments of the recruits for various medical procedures at the recruitment centers and at medical facilities outside the recruitment centers; queue regulations; exchanges of letters and documents, and submitting requests from clinics, hospitals, and government facilities.

The technical medical assistants are part of the medical committee. Prior to medical committee examinations, they measure vital signs and anthropometric values (such as height, weight, blood pressure, and pulse) and check visual acuity and color vision according to Ishihara color tables. Urinalysis testing is done by a laboratory technician. They also collect all previously sent documents, add all required forms, and provide all of this accumulated medical documentation and forms to the medical committee.

The physician's work on the medical committee consists of a thorough medical anamnesis, including family history, habits, and a psychological evaluation. A systematic and comprehensive physical examination is performed. According to the findings, the committee chairman decides whether additional tests, such as a specialist consultation, laboratory tests, imaging, or other measures, are required or if the information is sufficient to apply functional classification codes (FCCs) and complete a recruit's medical profile. The medical profile reflects the recruit's current health status and is used by the Personnel Directorate to assign a military position that is consistent with that health status. Similar to coding systems like the International Classification of Diseases (ICD), Medical FCCs describe disorders, their severity, and determine the profile (Chaiter et al., 2010). 
For a complete and successful medical process, a close collaboration between the medical, administrative and technical personnel and harmony in their working relationship are needed.

\subsection{Complex and dynamic medical processes at recruitment centers}

Based on our annual analysis of the last decade (Conscription Administration Data, 2001-9), each year about 100,000 new recruits start the medical processes, and more than 400,000 medical encounters are performed at the recruitment centers. About $50 \%$ and approximately $13 \%$ of the recruits have $\geq 2$ and $\geq 4$ encounters, respectively, mostly with specialists or in hospitals. Most recruits $(\geq 75 \%)$ have at least one FCC, while many $(\sim 20 \%)$ have 3 or more co-existent medical conditions, in spite of their age. Furthermore, it is not just the prevalence of medical conditions but also their severity and morbidity. For instance, $\sim 8 \%$ of recruits suffer from chronic asthma, while $\sim 1.5 \%$ and $\sim 10 \%$ suffer from various cardiac anomalies and mental disorders, respectively (Machluf et al., 2011). In about $10 \%$ of the recruits, the discovery of new conditions (following accidents, operations, or a change in the severity of the medical conditions from the first check-up) leads to the modification, addition, or cancellation of FCCs. This may result in the determination of a new medical profile. The thorough examination at a recruitment center might reveal a new, previously unknown, medical problem that warrants further follow-up or treatments at a primary clinic by the primary care physician. Among these conditions, we have revealed even cases of severe disorders, such cardiac anomalies, nephropathies, cancer, etc. In these cases, the diagnostictreatment loops need to be closed.

\subsection{Databases}

The information acquired during the medical process in stored, organized, and archived in a database. Computer-based tools allow analysis and visualization of data. With regard to the administrative aspects of the medical process, the computerized system consists of three main components (Machluf et al., 2011):

A status system: a specific status code is assigned to each file/recruit using code numbers reflecting the specific specialist, test, or documentation needed. A status code and its beginning and end dates allow the administrative medical department to actively and dynamically follow up and manage the medical and administrative processes on both the individual and collective levels.

An appointment system: this system is used to assign a specific date for an appointment to a certain specialist or medical procedure, to generate invitations, and to document the appointment outcome. Its design principles allow better control and management of human and medical resources according to the capacities and limitations of the medical system.

A directing, monitoring, and controlling system: a local smart card-based system for real-time follow-up and regulation of waiting lists of patients at each station. It automatically directs recruits either to an available station or according to priorities pre-set by the medical personnel that the specific recruit is required to pass. It provides the medical administrative personnel and the medical committee members with relevant information on both the individual (recruit) and collective (queues) levels.

Each component system is directed toward answering a particular need and, although each is independent, they are all compatible with each other and provide the user with a comprehensive view of the medical process and information. The combined computerized 
system improves the control and management of the medical processes and informatics from the point of view of both the patients and the system operators. Implementation and automation of medical regulations and procedures within the computerized system also make this system play a key role and serve as a control tool during the decision-making process (Machluf et al., 2011).

\section{Quality assurance and control system}

During 1997, a quality assurance and control system was set up (Chaiter et al., 2008; 2010; 2011; The State Comptroller and Ombudsman Office, 2002). This unique system, unlike most policies or systems for quality assurance of medical care, originated from within the medical profession, rather than from industry or academia, and its regulation and modes of action reflect the real daily health care activity in medical departments.

\begin{tabular}{|c|c|}
\hline $\begin{array}{c}\text { Goals } \\
\text { To assess components of the medical } \\
\text { process and committees' } \\
\text { performances and to ensure a } \\
\text { uniform and professional medical } \\
\text { process at recruitment centres }\end{array}$ & $\begin{array}{l}\text { Improvements } \\
\text { Medical committee' outcome } \\
\text { Knowledge and skills } \\
\text { Professional performance } \\
\text { Working environment } \\
\text { Uniform working platform } \\
\text { Patients' satisfaction }\end{array}$ \\
\hline $\begin{array}{l}\text { Tools } \\
\text { Observations } \\
\text { Re-examination (sampling) } \\
\text { Record evaluation (sampling) } \\
\text { Inferviews } \\
\text { Questionnaires } \\
\text { Reports \& data analysis } \\
\text { Patients' survey }\end{array}$ & $\begin{array}{l}\text { Intervention program } \\
\text { Lectures \& Instructions } \\
\text { Simulation center } \\
\text { Forum of organization leaders } \\
\text { Manuals \& Procedures } \\
\text { Renewal of medical equipment } \\
\text { Reports \& computerized tools } \\
\text { Certification }\end{array}$ \\
\hline $\begin{array}{l}\text { Assessment } \\
\text { Medical committee physicians } \\
\text { Administrative medical personnel } \\
\text { Technical assistants } \\
\text { Physical conditions \&. } \\
\text { Medical equipment and its use } \\
\text { Recruits } \\
\text { Computer-based assessment }\end{array}$ & $\begin{array}{l}\text { Analysis } \\
\text { Inadequacies in anamnesis quality } \\
\text { Insufficient physical examination } \\
\text { Errors in decision-making } \\
\text { Local administrative procectures } \\
\text { Inappropriate equipment and use } \\
\text { Inconsistencies in medical process } \\
\text { Prevalence of medical conditions } \\
\text { Computer-based assessment }\end{array}$ \\
\hline
\end{tabular}

Fig. 2. Scheme of the quality assurance and control project of medical processes at the recruitment centers.

The goals of the quality assurance and control committee are not solely to assess and improve the medical committee outcomes. They are also to identify the limitations and needs of whole medical process regarding the medical, technical, administrative, procedural, and physical aspects and to evaluate knowledge, skills, judgement and working patterns, which count for quality care (Holmboe et al., 2008), among all medical personnel; to develop and implement intervention programs to answer the needs of all of the parties participating in the medical process; and to achieve a higher quality of patient care and patient satisfaction (Fig. 2). Accordingly, the quality assurance and control system evaluates 
and analyzes in detail the various facets of the activities of the medical policy makers, managers, administrative staff, medical professionals (physicians, experts, consultants), and technical assistants, utilizing different complementary methods (Fig. 2). Experts from all these fields (and others), with their high skills and experience, are incorporated into the quality assurance and control system. Of note, performance measures are evidence-based and valid, feasible to collect, applicable to a large enough population of patients, attributed to the performance of individuals, adjustable to the patient level, and representative of the activities of a specialty (Landon et al., 2003).

\subsection{Approach}

Two main approaches are deployed by the quality assurance and control committee: (i) physical visits to recruitment centers, during which the procedures, work, decision-making processes, and outcomes are directly assessed, and (ii) data mining and processing from the computerized databases. The different means used in each approach to assess the work and results of the different medical process-related staff are summarized in Table 1. Incorporation of such complementary assessment methodologies provides both quantitative and qualitative analyses of daily activities and practices in the medical departments.

\begin{tabular}{|c|c|c|c|c|c|}
\hline \multicolumn{2}{|c|}{ Methodology } & \multicolumn{4}{c|}{ Components of the medical process } \\
\hline \multirow{2}{*}{ Approach } & Tools & $\begin{array}{c}\text { Medical } \\
\text { physicians }\end{array}$ & $\begin{array}{c}\text { Technical } \\
\text { assistants }\end{array}$ & $\begin{array}{c}\text { Administrative } \\
\text { staff }\end{array}$ & Recruits \\
\hline \multirow{4}{*}{$\begin{array}{c}\text { Direct } \\
\text { assessment }\end{array}$} & Observation & $\checkmark$ & $\checkmark$ & $\checkmark$ & - \\
\cline { 2 - 6 } & Re-examination & $\checkmark^{*}$ & - & - & - \\
\cline { 2 - 6 } & Record evaluation & $\checkmark$ & $\checkmark$ & $\checkmark$ & - \\
\cline { 2 - 6 } & Interviews & - & $\checkmark$ & $\checkmark$ & $\checkmark$ \\
\cline { 2 - 6 } & Questionnaires & $\checkmark^{*}$ & $\checkmark \#$ & $\checkmark \#$ & $\checkmark$ \\
\hline \multirow{2}{*}{ Data mining } & Reports-QC & $\checkmark$ & $\checkmark$ & $\checkmark$ & - \\
\cline { 2 - 6 } & Epidemiology-like & $\checkmark$ & $\checkmark$ & - & $\checkmark$ \\
\hline
\end{tabular}

*-distributed to recruits; " -distributed to soldiers

Table 1. The various methodologies used to assess components of the medical process.

\subsection{Direct assessment}

Direct assessment during the physical visits to the recruitment centers provides an opportunity to evaluate the work of the medical process as a whole. It also enables direct interaction and brainstorming with local medical department members, from administrative staff though technicians, physicians and experts to managers.

\subsubsection{Direct assessment of medical committee performance}

The medical committee is central to the medical process. Direct assessment of the medical committee's performance consists of direct observation and clinical evaluation of the physicians' work, random samplings, re-examination of recruits that were examined by the medical committee, distribution of questionnaires to recruits following their examination by the medical committee, and analysis of random samples of completed medical files.

Observation and clinical assessment (clinical audit): Upon receiving a recruit's consent, a physician from the quality and assurance system joins the medical committee as an observer 
and evaluates the completeness and adequacy of the anamnesis, physical examination, and decision-making process (using a pre-designed form), as well as the quality of the communication and service to the recruits. For each of these components, quantitative (a numerical scale following specific criteria) and qualitative (description and comments) assessments are used. For example, for each issue in the anamnesis or physical examination, codes are used to determine whether and how the issue was addressed (according to regulations and clinical merits as determined in the medical literature). The decision-making process is also assessed for the quality of referrals to further investigation and the quality of decision making according to clinical criteria and regulations.

For each medical committee, 5-10 cases are observed. Findings are shared and discussed with the observed physicians, and proper instructions and guidance are provided, if necessary.

Sampling for recruits' re-examination and record evaluation: With a recruits' consent, physicians from the quality and assurance system re-examine a random sampling (8-10 on average) of recruits immediately following their examination by the medical committee. The findings of the complete re-examination, including the "assigning" of a medical profile and FCCs, are compared to those of the local medical committee, and discrepancies are recorded and discussed for each case. In addition, a random sampling of files (30-50 files from each recruitment center), where the profiling process was completed, are re-checked by a physician from the quality and assurance system to assess the anamnesis, the medical findings and documents, the decision-making process, and the assignment of profiles and FCCs.

Questionnaire (patients' survey): In each recruitment center, questionnaires are randomly distributed to recruits (15-20 on average) following their examination by the medical committee to gain more insight regarding the medical processes (basic measurements, anamnesis, and physical examination), preserving medical confidentiality and right of privacy, as well as the recruits' rates of satisfaction with the service, during the medical process. Recruits are also asked to express their general impression of the medical process.

\subsubsection{Direct assessment of technical and administrative medical staff}

There are many similarities that are shared by the work of administrative staff and the technical assistants and also by their quality control and assessment. Direct assessment of each person's performance consists of direct observation and evaluation of their work, distribution of questionnaires to professional personnel, interviews, and analysis of random samples of completed medical files.

Observation (audit): The work of all of the technical medical staff is assessed prior to, during, and after the medical committee examinations. First, medical equipment (scales, altimeters, chart tables for the visual acuity examination, sphyngomanometers, and Ishihara color tables) and its use are examined during the process of taking basic measurements. Also, documentation handling, data recording, and proper directing to further processes are checked. When required, correct instructions are provided to prevent future mistakes. Similarly, observation of the administrative staff involves the same parameters, except for an evaluation of basic measurement techniques.

Questionnaire: A detailed questionnaire is used in order to evaluate the skills of all technical assistants in measurement techniques (weight, height, etc.), knowledge of the normal range and abnormal findings regarding different measurements and the corresponding FCCs (blood pressure, pulse, urinalysis, etc.), and administrative issues (recording of measurements and medical history, signatures, etc.). By contrast, questionnaires are given to 
the administrative staff to evaluate their knowledge of regulations (status, appointments, and the smart card-based system) and administrative issues (special populations, reports, etc.). Correct instructions are given and even demonstrations are done to promote an increase in knowledge and skills.

Interviews: The technical assistants and administrative personnel are interviewed about their work, the findings of the control system are discussed individually, and ideas of how to improve the infrastructure, process, and procedures are shared.

Sampling for records evaluation: a random sampling of files (10 on average of each kind, at each recruitment center), where the profiling process was completed, are re-checked by members of the quality and assurance system to assess the documentation and administrative processes.

\subsection{Data mining and processing}

The demographic information and medical-administrative data are stored, organized, and archived in a database. This data can be visualized and retrieved. Computerized tools, such as reports and regulation-based automated procedures, allow in-depth data analysis. Computerized databases and tools, when integrated into the medical process, allow efficient follow-up and management of medical processes and informatics (Machluf et al., 2011). These databases and reports can also serve as quality control and assessment means (Chaiter et al., 2008; 2010; Machluf et al., 2011; Navon et al., 2011). Using the reports, one can assess the work of medical professionals (physicians and experts, for example), technical assistants, and administrative staff members. For example, reports are aimed at identifying discrepancies between the medical information (such as anthropometric and basic measurement data) and FCCs or medical profiles, inconsistencies in the medicaladministrative information between the status and appointment systems, inadequate or incomplete medical processes (deviations from defined regulations), etc. (Chaiter et al., 2008; Machluf et al., 2011; Navon et al., 2011). Such populations, at the individual level, are monitored, and reports are distributed monthly to the relevant personnel at each recruitment center and to the managing authorities.

Reports also support the design, planning, monitoring, and use of human and medical resources and are a component of the decision making that is made by the medicaladministrative managers. For instance, various aspects of the availability and need for medical services, such as specialists, consultants, medical procedures, waiting queues, and various causes of congestion that need to be taken care of, are all assessed regularly by reports. The findings are distributed to the relevant personnel at the recruitment centers and to the managing authorities.

Reports also allow a comparison between the performance of the medical personnel within and between the recruitment centers and across a longitudinal time axis. Furthermore, since medical profiles and FCCs are indicators of medical conditions among recruits, an epidemiological investigation of the profile distribution and prevalence of FCCs can be performed, providing inter- and intra-recruitment center analysis (Chaiter et al., 2010). This valuable information can be related to or crossed with gender, geographical area, country of origin, ethnicity, socio-economic background, education, and morbidity trends in the general population in Israel and other countries.

\section{Findings}

Using these tools, we analyzed key parameters related to the performance, integrity, and completeness of the medical processes and procedures. Furthermore, we were able to 
identify difficulties concerning physical conditions, administrative or medical procedural deficiencies, and insufficient knowledge or skills of medical/technical/administrative personnel within the medical departments.

\subsection{Medical committee performance}

In general, during the years 1997-2010, more than sixty visits to the different recruitment centers were carried out. Regarding the performance of the medical committees, the work of more than 110 chairmen (of medical committees) was assessed by different means. Six hundred and fifty-five recruits were re-examined, 452 filled out questionnaires, and approximately 1700 records (medical files) were examined and evaluated, providing a 3pronged approach to observational findings. For the sake of clarity, we will present the findings from the first years and from the period after the intervention programs, focusing on recruitment centers with bigger populations.

During the first years of the program, we found that at most of the recruitment centers there was an inadequate amount or a lack of medical equipment, and often it was found that the equipment was used inappropriately (Chaiter et al., 2008). The following were among the more common medical equipment-related faults that were found: broken altimeters, inadequately balanced scales, unsuitable Ishihara books for color vision examination, incomplete regulation manuals, and inadequate equipment for visual acuity examinations. Following our visits, a major effort was made to improve the physical conditions and equipment at the medical committee examinations. Examination rooms were redesigned according to the needs of the physician and the patients. Inadequate and old medical equipment were replaced by new machines, complete manuals and regulations were provided, and attention was paid to the physical surroundings and environment. After a gradual improvement in this area throughout the recruitment centers, such faults, even minor ones, are now only rarely detected.

Among the physicians, we observed inadequacies in anamnesis quality, insufficient physical examinations, and errors in decision making (Chaiter et al., 2008). Furthermore, significant differences were observed between recruitment centers.

Anamnesis includes both specific tracer questions and general systematic queries. The tracer questions are all obligatory and refer to night vision, refractive eye surgery, dyslexia, drug use, gynaecological issues among female recruits, prolonged staying abroad at specific areas that are endemic to HIV, and psychological/psychiatric treatments. The main findings show a lack of anamnesis about most of these tracers, except the last two. Yet, differences were observed between recruitment centers. For instance (Chaiter et al., 2008), in 2002, complete anamnesis for refractive surgery was found to range between $12.5 \%$ of recruits at center 2 to $90 \%$ of recruits at center 5 ( $p<0.001)$. Anamnesis of drug use was found to be only $25 \%$ of the cases at center 2 as compared to $100 \%$ of the recruits at center $5(p=0.04)$. Similarly, at center $3,10 \%$ of recruits there were asked about dyslexia, while at center 2 the rate was $100 \%$ $(\mathrm{p}<0.001)$. During and especially following the intervention program, a clear improvement in the anamnesis process was evident by the completion of anamneses and specific tracer questions at all of the recruitment centers. For example (Chaiter et al., 2008), at center 1, the rates of recruits who were asked about the night vision trace and about prolonged stays abroad at specific areas that are endemic to HIV significantly increased (from $4.35 \%$ to $50 \%$ $(p=0.003)$ and from $8.7 \%$ to $50 \%(p=0.01)$ during the years 2006 and 2007).

Noted findings concerning physical examinations included a lack of examination of the lateral motion range of the spine and an incomplete examination of heart auscultation (at 
one point only - left sternal border), lung auscultation (one or two points on each side), the abdomen (partial palpation of one or two quadrants), the lower extremities (especially the feet), and male genitalia (lack of examination of the inguinal canal for possible inguinal hernia or incomplete examination of testicles) (Chaiter et al., 2008). Moreover, similar to anamnesis, clear differences were observed between recruitment centers. In 2002, the rate of complete examination of the abdomen ranged from $25 \%$ (center 2) to $90 \%$ (center 5) of recruits ( $p=0.048$ ), while complete foot examinations were carried out on $38 \%$ (center 4 ) to $70 \%$ (center 5 ) of recruits. During the years following the intervention program, noticeable progress was observed in the physical examinations. For example, at center 1, a significant improvement was noted from 2006 to 2007 in abdominal examinations (from $8.7 \%$ to $75 \%$ $(\mathrm{p}<0.001)$ ), foot examinations (from $47.8 \%$ to $100 \%(\mathrm{p}=0.01))$, and in male genitalia examinations (from $4.35 \%$ to $75 \%(\mathrm{p}<0.01)$ ).

Decision-making processes are integral and central to the medical process. Over the years, no clear trends were observed in the rates of correct decision-making procedures (Chaiter et al., 2008). This may be attributed to the turnover of human resources (chairmen, physicians), and the persistence of local medical procedures at recruitment centers which are not in line with the general guidance. Nevertheless, an improvement in the decision-making processes at specific time points, or over several years, at specific centers was associated with cooperation with the quality control and assurance system.

Together, better medical history recording, physical examinations, and decision-making processes by the physicians of the medical committees were noted.

Data mining and processing by computerized reports revealed a major decrease in the rate of discrepancies between the medical information (such as anthropometric and basic measurements data) and FCCs or medical profiles (Chaiter et al., 2008).

Analysis of medical profile distribution and the prevalence of FCCs, the indicators of medical conditions among recruits, uncovered significant differences between recruitment centers (Chaiter et al., 2010). Analyzing all of the FCCs revealed the 26 most common FCCs, which comprised approximately $90 \%$ of all assigned FCCs. Almost $90 \%$ of these common FCCs (23 out of 26) were found to vary significantly between different recruitment centers. Data stratification according to ethnic origin did not affect the results (Conscription Administration Data, 2001-9). These 26 FCCs include overweight, underweight, anemia, asthma, cardiac anomalies (either valvular or non-valvular), hypertension, varicocele/hydrocele, epilepsy, mental illness conditions (personality disorders, neurosis, psychosis, depression, mental retardation, and autism), hernia, visual acuity, allergic rhinitis/sinusitis, and flat feet. Some of these FCCs (such as bee sting allergy; anemia; valvular and non-valvular cardiac anomalies, including mitral valve prolapse; hypertension; hydrocele/varicocele; flat feet; hernia; hearing loss; visual acuity problems; and color blindness) were found not to significantly affect the final profile outcome. Yet, a set of only 8 FCCs (those indicating recruits who were underweight or suffered from asthma, chronic headache/migraine, mental illness, scoliosis/kyphosis, chronic back pain, knee joint disorders, or rhinitis/sinusitis) accounted for $90 \%$ of the medical profiling differences between recruitment centers (Conscription Administration Data, 2001-9). Of these key profile-affecting FCCs, the prevalence of all of them except scoliosis/kyphosis and mental conditions was found to be 1.5 to 2.5 times higher at recruitment center 1 as compared to the other centers (Chaiter et al., 2010).

Over the years, significant trends were observed: the prevalence of chronic headaches (increased), symptomatic scoliosis/kyphosis (increased), and active asthma (decreased) in 
recruitment center 1 (Table 2). Interestingly, a trend toward a significant increase in prevalence until the year 2005 and then a significant decrease in prevalence until the year 2009 was common to all other FCCs, except for that of underweight (Table 2).

\begin{tabular}{|c|c|c|c|c|c|c|c|c|c|c|}
\hline \multirow{2}{*}{ Medical condition } & \multicolumn{9}{|c|}{ Year } & \multirow{2}{*}{$\begin{array}{c}\text { Correlation } \\
\text { p value }\end{array}$} \\
\hline & 2001 & 2002 & 2003 & 2004 & 2005 & 2006 & 2007 & 2008 & 2009 & \\
\hline Chronic headache & 4.31 & 4.82 & 4.88 & 5.77 & 6.66 & 6.21 & 6.06 & 6.24 & 6.17 & $\begin{array}{l}0.820 \\
<0.01\end{array}$ \\
\hline $\begin{array}{c}\text { Symptomatic } \\
\text { scoliosis/kyphosis }\end{array}$ & 1.90 & 3.41 & 3.93 & 5.35 & 5.52 & 4.88 & 4.91 & 5.16 & 4.72 & $\begin{array}{l}0.709 \\
<0.05\end{array}$ \\
\hline Active asthma & 11.29 & 9.29 & 8.66 & 9.62 & 9.94 & 9.54 & 8.52 & 8.94 & 8.12 & $\begin{array}{l}0.684 \\
<0.05\end{array}$ \\
\hline Under-weight & 4.44 & 4.56 & 4.91 & 5.49 & 4.79 & 3.57 & 3.44 & 3.85 & 4.14 & $\begin{array}{c}0.558, \\
\text { n.s. }\end{array}$ \\
\hline Chronic back pain & 8.32 & 7.99 & 8.27 & 8.52 & 9.03 & 8.50 & 7.28 & 7.63 & 7.50 & $\begin{array}{c}0.515, \\
\text { n.s. }\end{array}$ \\
\hline $\begin{array}{c}\text { Allergic rhinitis/ } \\
\text { sinusitis }\end{array}$ & 11.89 & 11.75 & 11.19 & 12.39 & 12.86 & 12.31 & 11.18 & 11.19 & 10.30 & $\begin{array}{c}0.471, \\
\text { n.s. }\end{array}$ \\
\hline $\begin{array}{c}\text { Knee joint } \\
\text { disorders }\end{array}$ & 3.62 & 3.19 & 3.79 & 4.37 & 4.94 & 4.16 & 4.24 & 4.02 & 3.09 & $\begin{array}{c}0.082, \\
\text { n.s. }\end{array}$ \\
\hline Mental conditions & 9.83 & 8.17 & 9.14 & 8.94 & 11.13 & 10.20 & 10.03 & 9.75 & 8.10 & $\begin{array}{c}\text { 0.040, } \\
\text { n.s. }\end{array}$ \\
\hline
\end{tabular}

n.s. - not significant

Table 2. Percentages of main medical conditions contributing to a difference in profiling at recruitment center 1 from 2001 to 2009 (Modified with permission from Chaiter et al., 2010).

Some of these 26 FCCs were found to vary significantly between sub-districts in all of the recruitment centers (data not shown and Chaiter et al., 2010). This may be attributed to both demographic-environmental parameters and professional-human causes. Across recruitment centers, and over the years, clear and significant disparities were found in the prevalence of how a majority of these FCCs were assigned by different medical committee chairmen in the year 2006 (data not shown and Chaiter et al., 2010). This further strengthens the supposition that there are differences among recruitment centers and among the chairmen's reporting of medical histories, performing physical examinations, and interpreting various medical conditions, all of which lead to differential assignments of FCCs. Differences in FCC assignment by different chairmen at the same recruitment center indicate decision-making disparities or lack of experience and expertise in specific fields. The intervention program led to an improvement in certain aspects of the chairmen's knowledge and skills and, as a result, to an improvement in the performance of the committees; while variations between chairmen and between recruitment centers still exist, it is to a slightly lesser extent. The impact of professional development and understanding of the whole medical process (see below), as well as the establishment of a uniform working platform, resulted in decreased variability of medical conditions in the various conscription centers and among physicians. However, it could have been greater if the turnover of professional medical human resources would have been lower.

It is noteworthy that a subset of the 26 most commonly assigned FCCs were found to vary significantly among all three stratification criteria (recruitment centers, sub-districts, and 
chairmen assigning the profiles) (data not shown and Chaiter et al., 2010). The common characteristic of these FCCs (such as underweight, asthma, chronic headache, symptomatic scoliosis/hypnosis, chronic back pain, knee joint disorders, and allergic rhinitis/sinusitis) is that their assignment procedure is prone to a relatively high degree of variation in anamnesis, examination, chairman discretion, and interpretation.

\subsection{Technical assistant staff performance}

The work of more than 110 technician assistants and laboratory staff members was assessed by questionnaires, interviews, and direct observation of their performance before, during, and after the medical committee examinations (Conscription Administration Data, 2006-9; Chaiter et al., 2010; 2011). Prior to the intervention program, insufficient knowledge was revealed mainly with regard to the normal range of values for blood pressure and pulse, urinalysis, visual acuity, and color vision and to the interpretation of abnormal values of these measurements. Furthermore, some technician soldiers suffered from inadequate execution of the techniques, such as incorrect weight and height measurements. Inadequate knowledge regarding the relationship of all of the above mentioned measurements to specific medical FCCs was found. Some of these findings (insufficient knowledge, technical skill, and their relationships and meanings) were common to the technical staff at all of the recruitment centers, while other aspects were evident at specific recruitment centers.

After the intervention program, a higher level of expertise, increased skills in measuring medical parameters, and a more accurate interpretation of these values were observed among the technical staff. Improvements were found in the measurement techniques of weight, height, color vision tests, and determining of visual acuity, as well as an increased understanding of the normal parameters of these and other measurements, such as pulse and urinalysis, and their interpretation and relationship to medical FCCs (Chaiter et al., 2011). For example, in recruitment center 2, a significant and sustained improvement was observed in the interpretation of low systolic or diastolic blood pressure and in the determination of color blindness and other issues, and in recruitment center 1 there was a higher rate of correct measurements for weight, height, and visual acuity. The number of medical inconsistencies was progressively and dramatically reduced.

\subsection{Administrative staff}

During the years 2007 to 2009, 23 visits were carried out to assess the work of the administrative medical departments at the recruitment centers. During these visits, the work of almost 200 medical administrative personnel and managers was analyzed. The main findings (Navon et al., 2011) include incomplete knowledge of medical-administrative processes (such as appointments and statuses), a lack of professional collaboration between medical departments at different recruitment centers that was inevitably caused by differences in working patterns and operational procedures at all of the centers, a partial management of diaries with abnormal laboratory results, and local procedures which deviated and were not in line with regulations and instructions (such as those related to recruit identification or the management of medical questionnaires that were received from primary care physicians). Furthermore, in some cases, the managers of the medical administrative departments were only partially or inappropriately trained for their duty, and therefore their performance was far from optimal during the first period with regard to the professional-administrative-medical aspects and the management of human resources. 
As a result of the intervention program (Navon et al., 2011), improvements were found in all of these aspects of knowledge, skills, working procedures, professional collaboration, and management. This led to a considerable decrease in the rates of errors in records, such as inconsistencies in medical-administrative information between the status and appointment systems, and a significant increase in the rate of proper and complete administrative medical processes and profiling processes. Nevertheless, a significant increase was observed in the rate of recruits with medical profile that did not take into account the information written in the medical questionnaires that were filled out by their primary care physicians.

\subsection{Computer-based tools - not just for quality control and assurance}

The quality control and assurance system and the local medical departments at the recruitment centers continuously analyze data from the computerized system (mainly by means of reports) in order to assess and evaluate the performance of the medical and administrative processes, as well as to identify errors and discrepancies in individual medical files. In light of the findings, the medical committees and departments take action to correct mistakes, follow up specific populations, etc. Moreover, reports can uncover difficulties and vulnerabilities in global processes, which in turn lead to further improvements or modifications of either the medical procedure or the computerized medical database and system.

The combined computerized system (including the appointment system, the status system, and the directing, monitoring, and controlling system) improves the control and management of the medical processes and informatics from the point of view of both the patients and the system operators (Machluf et al., 2011). Different parameters of quality control regarding the medical and administrative processes are assessed (such as efficiency), and solutions are sought. Computerized system-based design and re-allocation of human and medical resources are implemented according to the capacities and limitations of the medical system. For instance, at recruitment center 1, reports during late '90s revealed a significant number of recruits waiting for specific medical processes (ophthalmologist, cardiologist, pulmonologist, orthopede, neurologist, etc.), and the intervention led to a reduction of at least $50 \%$ in the number of recruits holding a specific status over a period of 16 months; this reduction was achieved for most (12) of these statuses (15) (Machluf et al., 2011). In addition, analysis revealed the specialists in each recruitment center for which recruits wait long periods of time for successful completion of the process. In all of the recruitment centers, a higher number of recruits who were waiting for more than 3 months was found with recruits who were in the process of medical documentation (centers 1 and 5) or who were waiting to see a neurologist (centers 2-4). Also in this case, computer-aided planning and re-allocation of human and medical resources played a key role in the intervention and in the solutions found for the specific specialists and recruits at each center (Machluf et al., 2011). Another parameter regarding both quality control of the medical process and quality service to the recruits is the number of attendances at a recruitment center for each recruit until the final profile is assigned. Among the recruits who received their medical profile during 2010, approximately two-thirds of the recruits were required to report to the medical departments up to two times (Fig. 3). This rate was better in recruitment centers 2,4 , and 5 (>70\% of recruits). On the other hand, a considerable fraction of recruits were obligated to attend six times or more, especially in recruitment centers 1 and $5(2.5 \%$ and $2.3 \%$ of recruits, respectively) (Fig. 3). In some cases, the profile was assigned but no arrival to a recruitment center was recorded. These findings, and others, are the basis 
to analyze the medical and administrative aspects of the medical process, such as coordinated invitations, unnecessary or insufficient investigations, and the proper recording of arrivals.

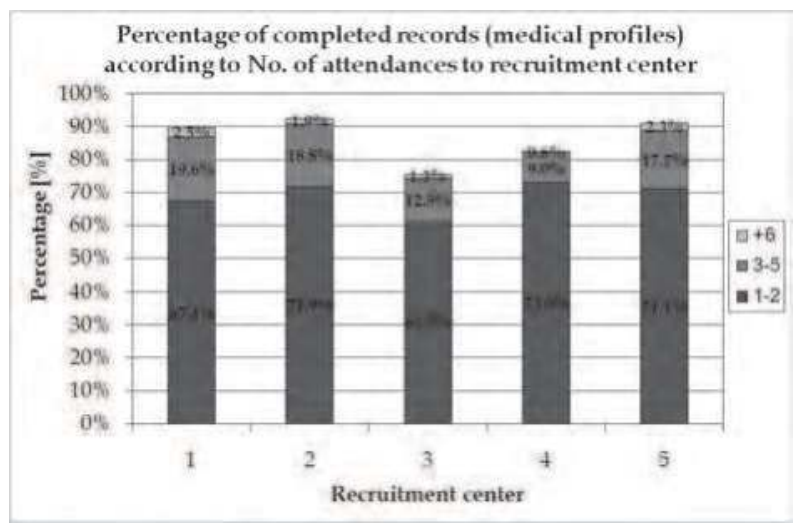

Fig. 3. Analysis of the number of attendances to a recruitment center in completed records during 2010.

The combined computerized system together with reports and automated tools allows the management of populations with special needs, such as mentally retarded and cerebral palsy patients. According to the regulations, these special populations are exempt from reporting to the recruitment centers, and their files are managed with maximum discretion and sensitivity to the individual, thus respecting them and their families' wishes.

Based on data mining findings, modifications were also introduced in working procedures. A reduction in the daily number of invited recruits improved the quality of the medical encounters. Specific combined status codes were introduced for the efficient planning of the medical encounters. Implementation and automation of medical regulations and procedures within the computerized system cause this system to play a key role and serve as a control tool during the decision-making process.

\section{Intervention}

The quality control and assurance system operates via an analysis $\rightarrow$ design $\rightarrow$ implementation $\rightarrow$ evaluation $\rightarrow$ modification loop.

First, all medical processes were mapped and analyzed, and particular infrastructure, medical, technical, management, and administrative needs were characterized by experts. The design principles of the intervention program with regard to the components, mode of action, time lines, etc. were determined to address those needs, in line with the general medical processes and goals. Then, a small-scale pilot program was launched in one recruitment center and was systematically analyzed. Throughout these steps, the quality control and assurance system personnel collaborated with the experts and experienced staff members from the medical departments and with policy makers. This collaboration allowed for better intervention planning, an efficient feedback process, contributed to the participants' sense of ownership and commitment to the process, increased their confidence, and made them receptive to the intervention program. After the required modifications 
were made, the same procedure was carried out as a large-scale intervention program that was gradually implemented at other recruitment centers, until full implementation of the system was achieved throughout the whole organization. The gradual implementation process allowed for both the full support of each recruitment center and an assimilation of adjustments to specific local needs.

It is noteworthy that acceptance of and cooperation with the quality control and assurance system were not trivial. During the first years of the program, physicians and policy makers, and to a lesser extent technical assistants and administrative staff members, were reluctant to comply with the quality control and assurance activities, during all of the stages and particularly during the intervention. The main reasons for that were professional autonomy and time/procedural requirements. This phenomenon and its causes were found also in France (Giraud-Roufast \& Chabot, 2008). To build trust and cooperation, except for the fact that it was an obligatory process, few key actions were taken. First, the main goals of performance assessment were to improve professional competence, rather than to take sanctions. Medical personnel were considered partners, taking part in activities and brainstorming (mainly during the design and implementation stages). During intensive educational activity, the benefits (professional development, money, time, resources, quality care, etc.) to the individual service-providing staff (physicians, managers, etc.) and to the patients (quality of service and care, safety, etc.), to the medical departments, and to the organization were highlighted. Gradually, quality control and assessment became an integral component of the medical department's work, both routinely by the medical personnel and occasionally by the quality control and assessment system.

Except for the physical condition issues, three main needs were acknowledged in every aspect of the medical processes, in the medical department: uniform medical and administrative processes at all recruitment centers; proper and comprehensive acquisition of medical, technical, and administrative knowledge, expertise, and skills; and sharing between all conscription centers. In light of these needs, an intervention program was designed. It utilizes various means:

Forums of organization leaders: A forum was established, which includes leading physicians, medical administrative personnel, and the managers of the medical departments. Meetings are held on a regular basis in order to update all involved personnel on the novelties introduced into the medical system, to exchange ideas, and to formulate recommendations (and thereafter their implementation) for ongoing quality assessment and improved working procedures. This led to the development and production of manuals for administrative and technician soldiers, the printing of a catalogue of medical equipment, and the initiation of theoretical and practical training programs.

Training and simulation center for physicians: A training program was implemented for physicians, which includes lectures, clinical training at a simulation center, and continuous observation and feedback on their work. Each chairman physician is invited once a year to participate in a workshop that provides simulated scenarios of patient-physician encounters. Each scenario is played by specially trained actors performing the role of the recruits. A detailed anamnesis, a recording of the findings, and further investigation is performed by the physician. Each encounter is recorded on video and is then discussed in detail with the special training team to point out mistakes and inconsistencies in the process. Each physician receives a personal feedback summary and accreditation is given for participation in the course. 
Instruction of physicians: After being observed, the physicians are instructed and trained in all issues assessed by the quality control and assurance system. Proper physical examination, partial or complete, is demonstrated upon request or, if necessary, is based on the findings. Manual for technical medical staff performance: A comprehensive manual was written describing measurement techniques that are carried out by the technical assistants (and laboratory staff) at the medical committee examinations. It was distributed to relevant personnel and is used on a daily basis. The manual also contains information about the normal range of systolic and diastolic blood pressure and pulse measurements and correct interpretation of visual acuity and color vision tests (Ishihara and D15), as well as about the interpretation of abnormal values with instructions of how to act if an abnormal value is encountered during measurement or is written in the medical committee protocol. The manual contains information that involves the technician soldiers in the coordination and quality assurance processes of the medical committee examinations. For instance, the technician soldiers are instructed to return a file to the physician if they find an abnormal blood pressure value recorded in the protocol of the medical committee without any instructions from the examining physician on how to proceed or if the physician determines the profile of the recruit without assigning a FCC that indicates hypertension.

Frontal lectures: All technical medical personnel and administrative staff at all of the recruitment centers were given lectures at each recruitment center and in special meetings arranged at the medical assessment branch of the IDF Medical Corps. The issues discussed in the lectures further stressed what was described in the written manuals and also emphasized cases of risk management in order to strengthen the notion about the importance of the technical medical staff's work and the administrative processes as part of the quality assurance of the medical committee examinations and as assistants of the physicians in the process of medical profiling. During some of the lectures at the recruitment centers, training in measurement techniques, such as blood pressure measurements, was performed. In addition, the relationships and links between the medical, technical, and administrative processes were highlighted.

Instruction of technical medical staff: After the observations, questionnaires, and interviews were conducted, the technician soldiers were given detailed feedback and were instructed and trained in all of the issues that were assessed by the quality control and assurance system. In addition, all problematic areas that were identified by the system were discussed with the medical department managers.

Instruction of administrative staff: After the observations, questionnaires, and interviews were completed, the administrative staff were given detailed feedback and were instructed and trained in all of the issues that were assessed by the quality control and assurance system. In addition, all problematic areas that were identified by the system were discussed with the administrative staff's managers.

Written reports: Written reports summarized the findings with an emphasis on the recommendations required to make improvements and to correct the mistakes found in each recruitment center. The reports were distributed to the relevant medical and management authorities at the local recruitment centers and at headquarters. These reports also allowed a comparative overview between medical departments at different recruitment centers and between different time periods or specific assessments.

Computerized tools: The quality control and assurance system plays a key role in the design and planning of computerized systems or in their modifications so that the medical department's needs, mainly with regard to procedures and regulations, will be answered. 
The quality control and assurance system also gives complementary support to the medical department with implementation, adjustments, and instruction in the proper use of the computerized tools in the medical processes for the purpose of higher quality of control, management, and service. The computerized system, through its implementation and automation of medical regulations and procedures, plays a central role and serves as a control tool during the decision-making process and as a way to prevent inconsistencies in the medical information. In addition, electronic medical files were incorporated into the computerized system.

Certification: Certification is virtually awarded for the completion of requisite training/instruction by accredited authorities, including the quality control and assurance system. It is important to note that, unlike most licensures and board certifications (Landon et al., 2003), the qualification process and examinations are periodic and specific to particular medical fields and ensure professional competency according to pre-determined standards.

\section{Effects of intervention}

During the years of intervention, benefits were observed in the quality of all of the areas that were examined. As these effects were described before (see the section entitled Findings) or earlier (Chaiter et al., 2008; 2010; 2011; Machluf et al., 2011; Navon et al., 2011), we can summarize them in a few main categories: 1) infrastructure and physical conditions; 2) consistent improvement in the knowledge, skills, and performance of the physicians (anamnesis, examination, decision-making processes, etc.), technicians (measurements, recording, interpretation, etc.), and administrative staff (procedures, regulations, etc.); 3) uniform working platforms and procedures in terms of the medical and administrative processes at all of the recruitment centers; and 4) a launching of the framework and forums for sharing knowledge and skills between all of the conscription centers.

One important contribution of the quality control and assurance system is in terms of the diagnosis, design, and implementation of the intervention program and its analysis. The impact on the medical department's performance is clear and evident. Furthermore, after the intervention program's implementation, the satisfaction rate, sense of belonging, and responsibility were higher among all of the medical department personnel. It led to the increased perception of the administrative and technical medical staff to feel that their work was part of the medical profiling process, acting as case managers and part of quality assurance aimed at providing the best medical service for recruits. Therefore, it is only natural that this would consequently lead to a consistent, major increase in the satisfaction level reported by recruits.

As mentioned above, not all of the goals were achieved fully, and in some respects there was a disparity between what was achieved and the desired objectives. Clearly, some changes are time-dependent, and the benefits of current efforts will be evident in the near future. Other challenges may require different solutions. We are always looking for new and better tools and modes of action to achieve these goals.

\section{Epidemiological aspects}

The medical processes for the adolescent population of Israel present a unique opportunity to assess the health status of the young Israeli population on a nationwide level and to identify risk factors that can affect present and future morbidity. 
A pilot study, including over 105,000 adolescents, has been carried out using data from one of the recruitment centers to assess trends in weight, height, and other medical parameters (e.g., blood pressure) and conditions (e.g., congenital heart disease) among 16-19 year olds in Israel (born in 1971-1992). Our preliminary analysis suggests that variability between recruitment centers may affect the consistency and reliability of nationwide analysis, as opposed to information from a single recruitment center. Furthermore, in one selected center, the differences between chairmen in assigning profiles and FCCs were much smaller than in other centers. Clear trends were demonstrated, and their association with demographic variables was examined. The findings are out of the scope of this manuscript, yet we wish to illustrate two possible insights drawn from such analysis.

\subsection{Anthropometric values}

Among the young (16-19 year olds) Israeli population born between 1971 and 1992, a significant increase in average body weight was demonstrated in females and mainly in males (Fig. 4, upper panel). In both genders, the increase in average weight is more dramatic in teenagers who were born during 1982-1992. On the other hand, no dramatic change was observed in average height in females or in males (Fig. 4, lower panel). This might be an indication of an increase in the body-mass index (BMI).
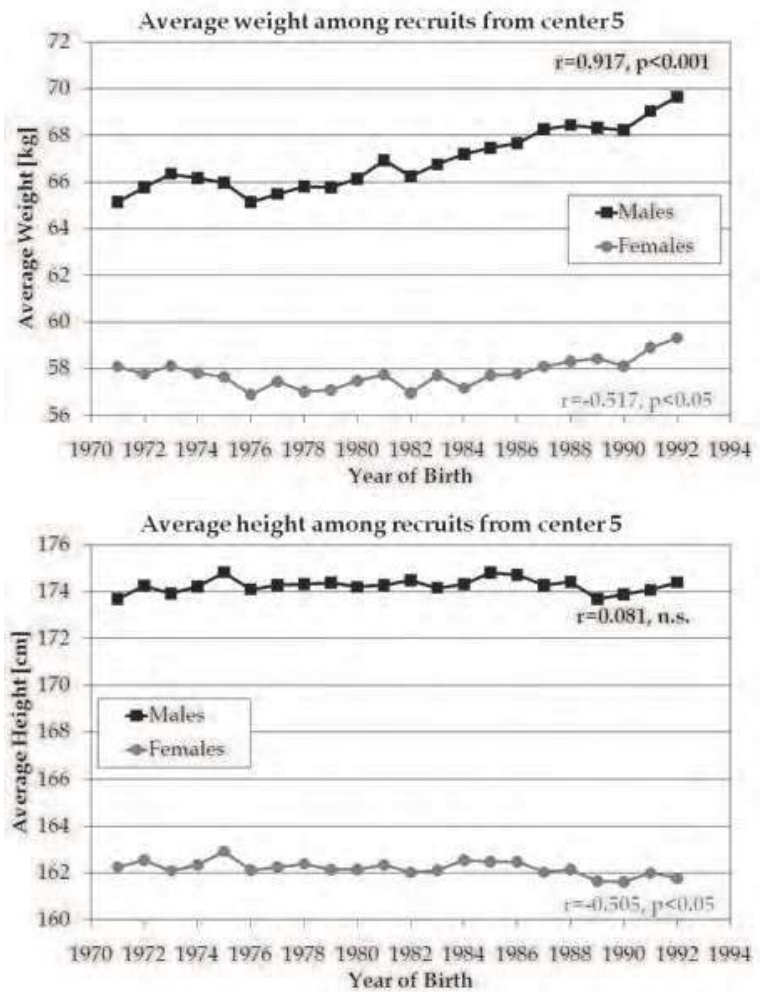

Fig. 4. Trends of average weight and height among the 16-19 year old Israeli population. 
General population data and military records suggest that US heights essentially remained stable after World War II (mainly in birth cohorts of 1955-74), which is concurrent with continual rapid increases in height in Western and Northern Europe (Komlos \& Lauderdale, 2007). A historical retrospect of German military male recruits found an increase in both the average body weight and height, where the changes in body weight were greater than those of body height (Jaeger et al., 2001).

The implications of these findings with regard to different demographic parameters, socioeconomic status, anthropometric indices, medical conditions, and other risk factors are now under investigation.

\subsection{Medical conditions}

Analysis of the prevalence of specific FCCs provided the opportunity to gain knowledge about the trends of different medical conditions. Such an analysis in recruits from center 5 uncovered an increase in the prevalence of valvular and non-valvular congenital heart anomalies among male recruits (Fig. 5. upper panel). Referring to cardiac diseases, the prevalence of congenital valvular heart disorders was higher than the prevalence of nonvalvular heart disorders. Furthermore, an increase in the prevalence of solid tumors in both males and females was also demonstrated (Fig. 5. lower panel).
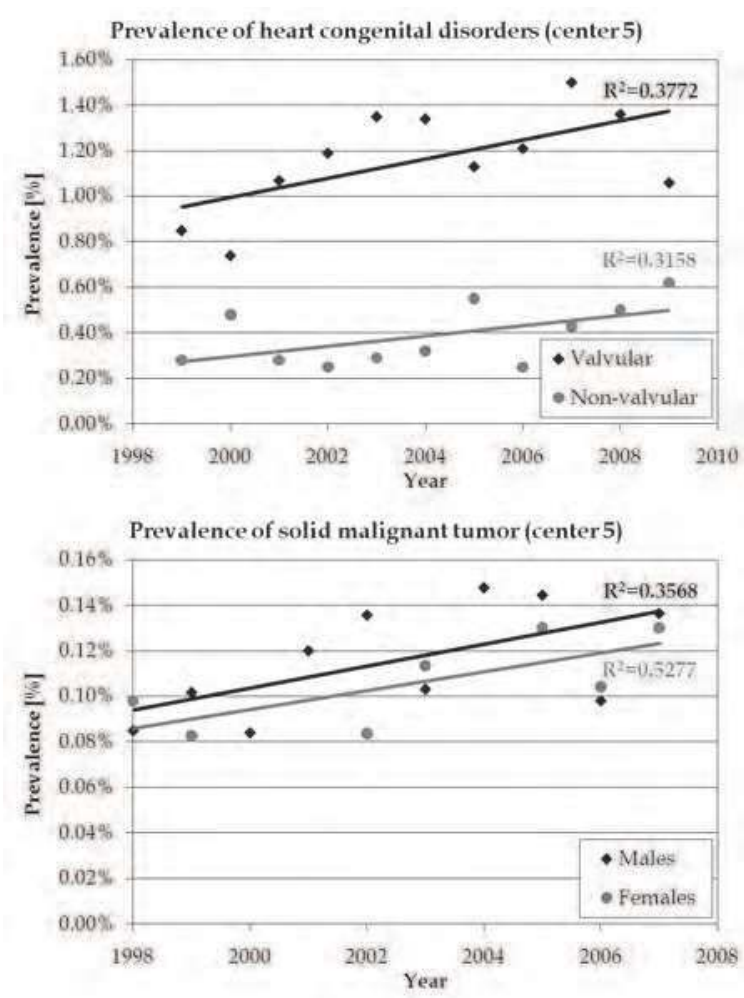

Fig. 5. Prevalence of solid tumors and congenital heart anomalies among the 16-19 year old Israeli population. 
Previous analyses of specific morbidity prevalence in Israeli conscripts from all recruitment centers also revealed an increase in the prevalence of heart defects among male recruits (Farfel et al., 2007), as well as a higher prevalence of congenital valvular heart disease compared to non-valvular heart disease (Bar-Dayan et al., 2005).

\section{A nationwide program}

These findings demonstrate the need for a nationwide intervention program to reduce morbidity, future illness, and even mortality. Furthermore, a project of information sharing and cooperation was established with family physicians at primary clinics on a nationwide basis, the Ministry of Health, the National Insurance Institute, the Israeli National Cancer Registry, and the Ministry of Social Affairs and Social Services. This national project (Fig. 6) is aimed at education, prevention, and early intervention in target populations.

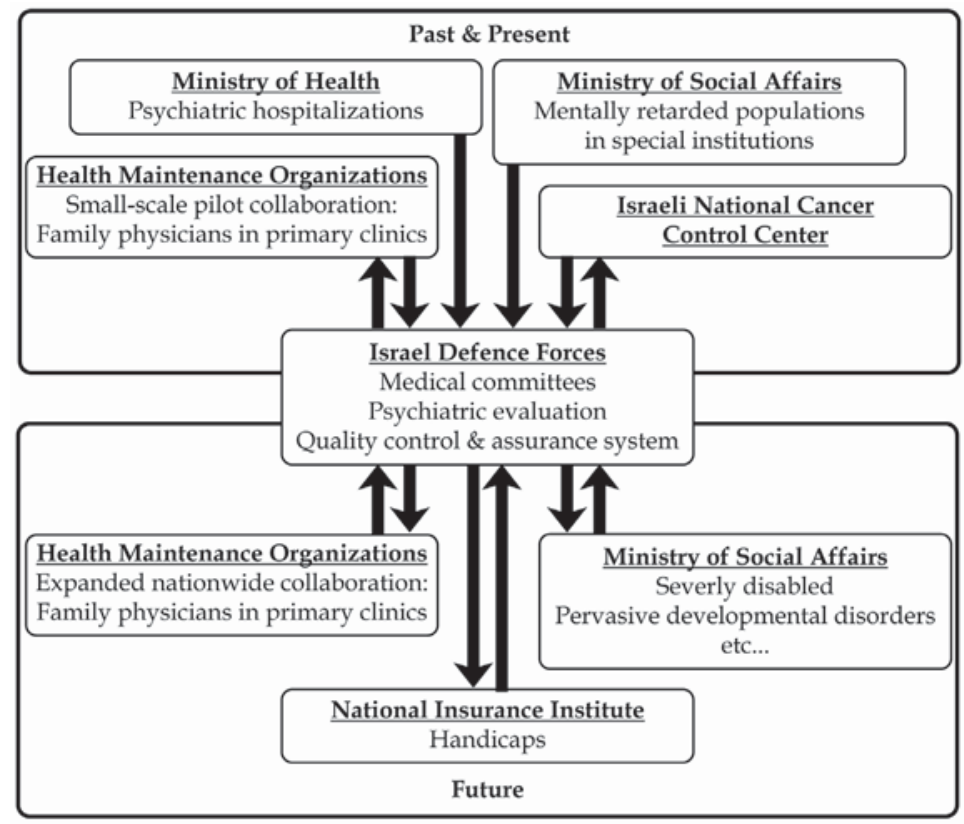

Fig. 6. Scheme of national project for information sharing and collaboration.

So far, although this information-sharing project was only initiated on a small-scale pilot format, covering only a minor fraction of the relevant population, bi-directional benefits are evident. For example, medical investigations in recruitment centers uncover medical conditions that were unknown before to the civilian authorities and vice-versa. These medical conditions include vision and hearing problems, essential hypertension, asthma, cardiac anomalies, tumors, urological conditions (hernia, varicocele, hydrocele, etc.), nephrological disorders (nephropathies, microscopic hematoria, severe proteinuria, etc.), orthopaedic problems, neurological problems, and mental disorders. Such findings are then reported to the primary care physician for further investigation with a referral to specialists and/or for treatment. The medical departments at the recruitment centers are then informed 
about further findings and about any change in the medical condition and status of the recruit by the primary physicians. Beyond the issue of medical informatics and process, recruits are provided with better medical service, which might contribute to early diagnosis, quick and appropriate treatment, and better and faster recovery. In the future, if this information sharing is combined with an epidemiological study, we believe it may also contribute to the prevention of health conditions, either via the medical education of teenagers or by active medical intervention.

\section{Concluding remarks}

Quality assessment, control, and improvement in a health system should include the infrastructure and structure, process, and outcome levels. The quality control and assurance system for medical committees at recruitment centers operates via an analysis $\rightarrow$ design $\rightarrow$ implementation $\rightarrow$ evaluation $\rightarrow$ modification loop. It first relies upon the identification of the limitations and needs of the whole medical process and of each department with regard to the medical, technical, administrative, procedural, and physical aspects and with regard to official policy, including the systematic evaluation of the knowledge, skills, judgement, and working patterns of all of the medical personnel. To this end, complementary methodologies are utilized to provide both quantitative and qualitative analyses of daily activities and practices. Among the main tools utilized are observations and assessment, a sampling of recruits for re-examination and of records for evaluation, questionnaires, interviews, data mining and analysis by reports, and patients' surveys. Then, intervention programs are designed and implemented to answer the needs of all of the parties participating in the medical process in order to improve their quality and performance; to increase the quality of patient care; and to achieve a higher patient satisfaction rate. Intervention programs include the establishment of a training and simulation center, lectures and instruction to all of the medical department's personnel, a forum of organization leaders, production of manuals, certification, written reports, and the design of computerized tools. These intervention programs and their impact need to be continuously evaluated and modified according to the specific needs and effects in particular recruitment centers. Significant improvements have been observed in various key parameters, such as the knowledge, skills, and judgement of the personnel and their professional performance, the conditions of their working environment, uniform working platforms, and the patients' satisfaction rate. Incessant monitoring and intervention are important to maintain quality in a medical organization.

Quality improvement at the individual (physicians, assistant technicians, administrative staff, managers, etc.) and global levels (performance, outcomes, physical conditions, procedures and regulations, etc.) is a goal in and of itself but is also a means of improving patient care and safety. Furthermore, the collaboration of all the participants in the process, on all levels - medical professionals (physicians, experts, etc.), technical assistants, administrative staff, and the active support and involvement of the managing authorities and policy makers - is a critical determinant for a successful outcome.

The successful application of a quality control and assurance project can lay the foundation for a population-based investigation, namely an assessment of the health status of the young Israeli population, by measuring anthropometric values and the prevalence of various medical conditions among recruits on a nationwide level. They may result in the identification of risk factors that can affect present and future morbidity. A national project 
of information sharing and cooperation was set up, aimed at screening, education, prevention, and early intervention in target populations.

There are multi-directional effects and relationships between the quality assurance and control process and its implications on improving the quality of health care and nationwide projects of preventative medicine through collaboration and information sharing (Fig. 7).

Recently, Zalmanovitch and Vashdi (2010) proposed an inherent trilemma, a trade-off between three desirable objectives (Iverson \& Wren, 1998), in any debate on health care policy. In this context, the critical broad objectives are quality, funding, and coverage. In this context, quality refers to the efficiency and effectiveness of the health care services provided; funding refers to the public expenditures for health care that are incurred by taxpayers; and coverage refers to the percentage of a country's population eligible for state health care services and the comprehensiveness of these services. A trade-off means that, at most, only two of the three objectives can be satisfied simultaneously, and satisfying any two will always come at the expense of the third (Zalmanovitch \& Vashdi, 2010). The cumulative experience of the quality assurance and control system and its effects suggest that it is central to the successful balancing between the three objectives, at least in the context of the medical departments at the recruitment centers. Considering the common characteristics of medical processes at the recruitment centers and at primary medical facilities, implementation of multi-armed quality assurance and control systems at clinics and hospitals holds great promise in finding the best solution to the trilemma, beyond the direct and clear impact on the medical staff's performance, medical process outcomes, service quality, and patient safety. Together with an epidemiologic investigation and preventive action, this system may contribute to the identification of risk factors and a reduction in future morbidity.

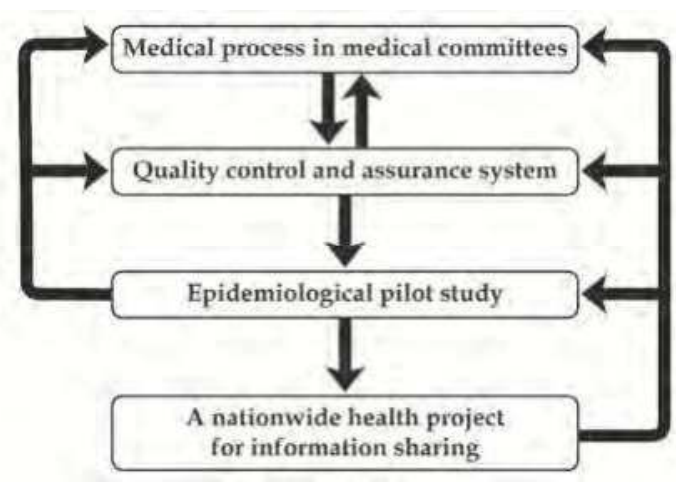

Fig. 7. Establishment of a quality control and assurance system for medical processes in recruitment centers led to an epidemiological study and a nationwide health project.

It remains to be seen in future studies whether the system can efficiently address these issues.

\section{References}

Blumenthal, D. (1996). Quality of health care part 1: Quality of health care - what is it?. The New England Journal of Medicine, Vol.335, No.12, pp. 891-4. 
Bar-Dayan, Y.; Elishkevits, K.; Goldstein, L.; Goldberg, A.; Ohana, N.; Onn, E.; Levi, Y. \& Bar-Dayan, Y. (2005). The prevalence of common cardiovascular diseases among 17-year-old Israeli conscripts. Cardiology, Vol.104, No.1, pp. 6-9.

Campbell, S.M.; Roland, M.O. \& Buetow, S.A. (2000). Defining quality of care. Social Science and Medicine, Vol.51, No.11, pp. 1611-25.

Chaiter, Y.; Machluf, Y.; Pirogovsky. A.; Palma, E.; Yona, A.; Shohat, T.; Yitzak, A.; Tal, O. \& Ash, N. (2010). Quality control and quality assurance of medical committee performance in the Israel Defense Forces. International Journal of Health Care Quality Assurance, Vol.23 No.5, pp. 507-15.

Chaiter, Y., Palma, E., Machluf, Y., Yona, A.; Cohen, A.; Pirogovsky, A.; Shohat, T.; Ytzhak, A. \& Ash, N. (2011). Quality assuring intervention for technical medical staff at medical committees. International Journal of Health Care Quality Assurance, Vol.24, No.1, pp. 19-30.

Chaiter, Y.; Pirogovsky, A.; Palma, E.; Yona, A.; Machluf, Y.; Shohat, T.; Farraj, N.; Tal, O., Campino-Abbebe, G. \& Levy, Y. (2008). Medical quality control in conscription centers- ten years of activity. Journal of Israeli Military Medicine, Vol.5 No.2, pp. 75-9.

Conscription Administration Data. (2001-9), Biannual control on medical profiles in recruitment centers, Personnel Directorate, IDF, Israel (unpublished data analysis).

Donabedian, A. (2003). An introduction to quality assurance in health care, Oxford University Press, ISBN 0195158091, New York, USA.

Donabedian, A. (2005). Evaluating the quality of medical care. Milbank Quarterly, Vol.83, No.4, pp. 691-729.

Dye, T.R. (1987). Understanding Public Policy (6 $6^{\text {th }}$ edition), Prentice-Hall, ISBN 0139369732, Englewood Cliffs, New Jersey, USA.

Farfel, A.; Green, M.S.; Shochat, T.; Noyman.; Levy, Y. \& Afek, A. (2007). Trends in specific morbidity prevalence in male adolescents in Israel over a 50 year period and the impact of recent immigration. The Israel Medical Association Journal, Vol.9, No.3, pp. 149-52.

Giraud-Roufast, A. \& Chabot, J.M. (2008). Medical acceptance of quality assurance in health care, The Journal of the American Medical Association, Vol.300, No.22, pp. 2663-5.

Holmboe, E.S.; Lipner, R. \& Greiner, A. (2008). Assessing quality of care: knowledge matters, The Journal of the American Medical Association, Vol.299, NO.3, pp. 338-40.

Iverson, T. \& Wren, A. (1998). Equality, employment, and budgetary restraint: the trilemma of the service economy. World Politics, Vol.50, No.4, pp. 507-46.

Jaeger, U.; Zellner, K.; Kromeyer-Hauschild, K.; Lüdde, R.; Eisele, R. \& Hebebrand, J. (2001). Body height, body weight and body mass index of German military recruits. Historical retrospect and current status. Anthropologischer Anzeiger, Vol.59, No.3, pp. 251-73.

Komlos, J. \& Lauderdale, B.E. (2007). The mystery trend in American heights in the $20^{\text {th }}$ century. Annals of Human Biology, Vol.34, No.2, pp. 206-15.

Landon, B.E.; Normand, S.L.; Blumenthal, D. \& Daley, J. (2003). Physician clinical performance assessment: prospects and barriers, The Journal of the American Medical Association, Vol.290, No.9, pp. 1183-9.

Machluf, Y.; Pirogovsky, A.; Palma, E.; Yona, A.; Navon, A.; Shohat, T.; Ytzhak, A.; Tal, O.; Ash, N.; Nachmann, M. \& Chaiter, Y. (2011). Coordinated computerized systems aimed at management, control, and quality assurance of medical processes and 
informatics. International Journal of Health Care Quality Assurance, Accepted for publication.

Mandel, D.; Amital, H.; Zimlichman, E.; Wartenfeld, R.; Benyamini, L.; Shochat, T.; Mimouni, F.B. \& Kreiss, Y. (2004). Quality assessment program in primary care clinics: a tool for quality improvement. International Journal for Quality in Health Care, Vol.16, No.2, pp. 175-80.

Mandel, D.; Zimlichman, E.; Ash, N., Mimouni, F.B.; Ezra, Y. \& Kreiss, Y. (2003). Quality assessment of primary health care in a military setting, Milltary Medicine, Vol.168, No.11, pp. 890-2.

Munro, R.A. (2009). Lean six Sigma for the healthcare practice: A pocket guide, Amer Society for Quality Press, ISBN 0873897609, Milwaukee, Wisconsin, USA.

Navon, A.; Machluf, Y.; Cohen, A.; Pirogovsky, A.; Palma, E.; Tal, O.; Frenkel-Nir, Y.; Ash, N. \& Chaiter, Y. (2011). Quality Assurance of Administrative Aspects of Medical Processes within the Framework of Medical Committees. Journal of Israeli Military Medicine, Accepted for publication.

Ovretveit, J. (1992). Health service quality: An introduction to quality methods for health services, Blackwell Scientific Publications, ISBN 0632032790, Oxford, England.

Ransom, E.R.; Joshi, M.S.; Nash, D.B. \& Ransom, S.B. (2008). The Healthcare Quality Book: Vision, strategy, and tools (2nd edition), Health Administration Press, ISBN 1567933017, Chicago, USA.

The State Controller and Ombudsman Office. (2002). Annual Report 53a, Israel.

Zalmanovitch, Y. \& Vashdi, D.R. (2010). Trade-offs are unavailable. British Medical Journal, Vol.340, pp. c1259. 


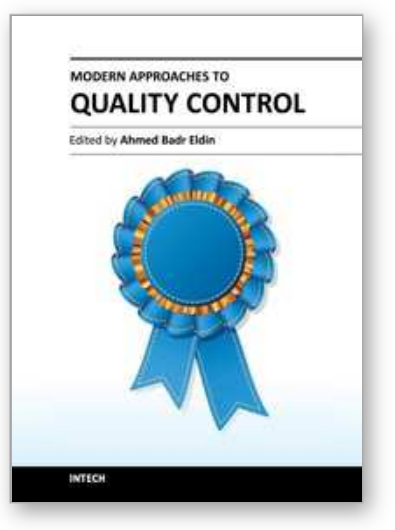

\author{
Modern Approaches To Quality Control \\ Edited by Dr. Ahmed Badr Eldin
}

ISBN 978-953-307-971-4

Hard cover, 538 pages

Publisher InTech

Published online 09, November, 2011

Published in print edition November, 2011

Rapid advance have been made in the last decade in the quality control procedures and techniques, most of the existing books try to cover specific techniques with all of their details. The aim of this book is to demonstrate quality control processes in a variety of areas, ranging from pharmaceutical and medical fields to construction engineering and data quality. A wide range of techniques and procedures have been covered.

\title{
How to reference
}

In order to correctly reference this scholarly work, feel free to copy and paste the following:

Yossy Machluf, Amir Navon, Avi Yona, Avinoam Pirogovsky, Elio Palma, Orna Tal, Nachman Ash, Avi Cohen and Yoram Chaiter (2011). From a Quality Assurance and Control System for Medical Processes, Through Epidemiological Trends of Medical Conditions, to a Nationwide Health Project, Modern Approaches To Quality Control, Dr. Ahmed Badr Eldin (Ed.), ISBN: 978-953-307-971-4, InTech, Available from:

http://www.intechopen.com/books/modern-approaches-to-quality-control/from-a-quality-assurance-andcontrol-system-for-medical-processes-through-epidemiological-trends-of-

\section{INTECH}

open science | open minds

\section{InTech Europe}

University Campus STeP Ri

Slavka Krautzeka 83/A

51000 Rijeka, Croatia

Phone: +385 (51) 770447

Fax: +385 (51) 686166

www.intechopen.com

\section{InTech China}

Unit 405, Office Block, Hotel Equatorial Shanghai

No.65, Yan An Road (West), Shanghai, 200040, China

中国上海市延安西路65号上海国际贵都大饭店办公楼 405 单元

Phone: +86-21-62489820

Fax: +86-21-62489821 
(C) 2011 The Author(s). Licensee IntechOpen. This is an open access article distributed under the terms of the Creative Commons Attribution 3.0 License, which permits unrestricted use, distribution, and reproduction in any medium, provided the original work is properly cited. 